VARIA

\title{
Éric Weil e a Filosofia do direito de Hegel ${ }^{1}$
}

\author{
Éric Weil and Hegel's Philosophy of right
}

\author{
Patrice Canivez \\ https://orcid.org/0000-0001-8105-5051 - E-mail: patrice.canivez@univ-lille.fr
}

\begin{abstract}
RESUMO
Este artigo trata da relação do pensamento político de Eric Weil com a Filosofia do Direito de Hegel, a partir de dois textos de Eric Weil: "Hegel e o Conceito de Revolução" e "A Filosofia do Direito e a Filosofia da História Hegeliana", traduzidos e publicados no Brasil em um volume intitulado Hegel e nós. $\mathrm{O}$ artigo inicialmente analisa esses dois textos. O primeiro, mostra como o conceito hegeliano de revolução incide mais sobre a "situação revolucionária" - sua problemática - do que sobre a revolução como acontecimento. Isso permite apreender distinções fundamentais em Éric Weil, como a diferença entre revolta e revolução e as duas modalidades de revolução: uma baseada num movimento de massa, a outra que um governo responsável deve implementar para lidar com as mudanças necessárias antes que elas sejam impostas por uma revolta violenta. O segundo texto, situa a Filosofia do Direito na teoria hegeliana da história. Isso permite diferenciar entre a atitude teórica de Hegel, da qual procede uma compreensão essencialmente especulativa da história, e a abordagem de Eric Weil que enfatiza a ação. A partir da análise desses dois textos e sublinhando o contexto histórico em que Éric Weil desenvolve seu próprio pensamento, o artigo oferece elementos de comparação e diferenciação entre a Filosofia do Direito hegeliana e a Filosofia Política publicada por Eric Weil em 1956.
\end{abstract}

Palavras-chave: Hegel. Filosofia do direito. Revolução. Filosofia da história. Eric Weil.

\footnotetext{
1 Artigo traduzido por Marcelo Perine, Doutor em Filosofia e Professor da PUC-SP.
} 


\section{ABSTRACT}

This article deals with the relationship of Eric Weil's political thought with Hegel's Philosophy of Law, based on two texts by Eric Weil: "Hegel and the Concept of Revolution" and "The Philosophy of Law and the Hegelian's Philosophy of History", translated and published in Brazil in a volume entitled Hegel e Nós. The article analyzes these two texts. The first shows how the Hegelian concept of revolution focuses more on the revolutionary situation - its problematic - than on revolution as an event. This allows us to apprehend fundamental distinctions in Éric Weil, such as the difference between revolt and revolution and as two modalities of revolution: one based on a mass movement, the other that a responsible government must implement to deal with the necessary changes before they are imposed by a violent revolt. The second text places the Philosophy of Law in the Hegelian theory of history. This allows us to differentiate between Hegel's theoretical attitude, from which an essentially speculative understanding of history proceeds, and Eric Weil's approach, which emphasizes action. From the analysis of two texts and according to the historical context in which Éric Weil develops his own thought, the article offers elements of comparison and differentiation between the Hegelian Philosophy of Law and Political Philosophy published by Eric Weil in 1956.

Keywords: Hegel. Philosophy of Law. Revolution. Philosophy of History. Eric Weil.

\section{Posição do problema}

Essa exposição tem como objeto a interpretação de Éric Weil da Filosofia do Direito de Hegel, a partir de dois textos traduzidos e publicados no volume Hegel e nós: "Hegel e o conceito da revolução" e "A Filosofia do direito e a filosofia da história hegeliana". Cada um à sua maneira, os dois textos referem-se à história. Em "Hegel e o conceito da revolução" ${ }^{2}$, trata-se da história no sentido de "situação histórica". O texto trata da relação do pensamento político de Hegel com sua época. Weil mostra como Hegel estava interessado na revolução no sentido de "situação revolucionária" mais do que no evento da revolução. Também é significativo que o texto insista na noção de "situação revolucionária" enquanto o título anuncia o "conceito da revolução". Isso significa que para Hegel, como o lê Weil, o verdadeiro conceito da revolução deve permitir-nos compreender a situação revolucionária. Em outras palavras, a revolução como conceito se aplica a uma "problemática" mais do que a uma cadeia de eventos ou a um método de ação.

Já o texto intitulado "A Filosofia do direito e a filosofia da história hegeliana" trata da história no sentido de história universal (a Weltgeschichte), ou seja, a história do gênero humano. Mais especificamente, trata da história das sociedades humanas e dos Estados de que são dotadas. O fato significativo aqui é que na obra publicada pelo próprio Hegel - portanto, sem contar as lições publicadas após sua morte - a filosofia da história forma o capítulo final da Filosofia do Direito. Isso significa que a história universal é para Hegel essencialmente uma história política. Além disso, a Filosofia do Direito é o desenvolvimento da parte da Enciclopédia das Ciências Filosóficas dedicada ao Espírito objetivo. O que segue o Espírito objetivo, no sistema

\footnotetext{
2 Os textos originais dos artigos em francês constituem os capítulos VII e VIII de Philosophie et réalité, vol. I (Paris, Beauchesne, 2003). As referências a esses dois artigos serão dadas pela edição eletrônica da tradução brasileira: Hegel e nós: Éric Weil, com a abreviação HN seguida do número da página.
} 
hegeliano, é o Espírito absoluto: é o Espírito presente a si mesmo na religião, na arte e na filosofia. Resumindo a análise de Weil, podemos dizer que a filosofia da história, ao final da Filosofia do Direito, prepara o caminho para a passagem ao Espírito absoluto. Isso significa que a filosofia do direito de Hegel e sua filosofia da história pretendem mostrar em que condições históricas, sociais e políticas a filosofia é possível - a filosofia na forma que assumiu em Hegel, isto é, na forma de saber especulativo. Foi necessário que primeiro o Espírito se tenha realizado no mundo para que ele pudesse em seguida se apreender na forma de discurso conceitual. É o tema da filosofia que apreende seu tempo no pensamento.

Voltarei a esses textos em minha exposição, que consistirá em três partes de dimensões desiguais. A primeira parte mais longa será dedicada ao texto intitulado "Hegel e o conceito de revolução" (I). Duas outras partes mais curtas serão dedicadas, respectivamente, ao texto "A Filosofia do direito e a filosofia da história hegeliana" (II), e, à relação entre a Filosofia do direito de Hegel e a Filosofia política de Éric Weil (III).

\section{"Hegel e o conceito da revolução"}

Hegel (1770-1831) viveu uma época de revoluções: não só na França, quando ainda não tinha vinte anos, mas em toda a Europa quando tinha mais de cinquenta: revoluções na França, Bélgica, Itália, Grécia, Rússia. Hegel é também testemunha do início da revolução industrial na Inglaterra, à qual fazem eco certos parágrafos da Filosofia do direito.

\section{Uma época de viragem na história da humanidade}

Essa é uma época de viragem: é o fim de um mundo e o início de um novo. É uma virada na história da humanidade. Éric Weil cita a respeito as Lições sobre a filosofia da história de Hegel. Não retomo essa longa passagem por completo. Retenho apenas as seguintes frases: "o homem se põe na cabeça, isto é, no pensamento e edifica a realidade sobre ele. Anaxágoras foi o primeiro que disse que o Noûs governa o mundo, mas é somente agora que o homem chegou a ponto de reconhecer que o pensamento deve governar a realidade espiritual (geistige Wirklichkeit)" (HEGEL, 1923, p. 926; HN, p. 132 s.). A "realidade espiritual" é claramente o que Hegel chama de Espírito objetivo, isto é, realidade social e política. É o conjunto de instituições que estruturam a sociedade e o Estado, mas também são as representações coletivas e as convicções morais de seus membros. Em poucas palavras: tudo o que a Filosofia do direito hegeliana chama de Sittlichkeit - em termos weilianos: "moral concreta", a moral viva e vivida que regula a vida cotidiana e lhe dá sentido. O que é revolucionário para Hegel é o fato de que o ser humano possa reformar o mundo em que vive. Reformá-lo no sentido estrito do termo, isto é, re-formá-lo, dar-lhe uma nova forma. Acima de tudo, o fato essencial é que ele possa fazê-lo de acordo com as exigências da razão, em conformidade com o pensamento. $O$ mundo social e político pode agora ser reformado, com pleno conhecimento de causa, por meio de uma teoria racional do direito e da justiça. A razão poderá pôr fim ao reino da injustiça, especialmente a injustiça que perdura pela força da tradição, que se perpetua de geração em geração, impondo-se como uma ordem aparentemente imutável.

Hegel caracteriza este "momento na história do mundo" (HEGEL, 1923, II, 931; HN, p. 133), como o momento em que se tinha "efetuado a real e eficaz (wirkliche) reconciliação do divino com o mundo" (HN, p. 133). Isso se explica pelo fato de que o divino, para Hegel, é a própria razão. A reconciliação do divino com o mundo é a transformação do mundo existente em função de uma demanda por justiça. É por isso que Weil comenta: 
uma nova época começa, uma outra terminou precisamente porque o princípio que foi somente fermento do que precedia, o da busca cristã, mais precisamente luterana, da justiça e da razão no mundo e não em um além, foi enunciado, compreendido, aplicado, e porque o homem que elevou à consciência o que antes o dominava de maneira inconsciente, não é mais o homem que tinha sido até então, porque ele agirá de outro modo (HN, p. 133).

Que ele agirá de outro modo: isso significa que ele agora agirá de forma consciente, sabendo claramente o que quer e por que o quer. Mas também significa que, sabendo agora o que quer, pode realizá-lo por meio da ação consciente e deliberada, e não mais inconscientemente pelos meios da paixão e da violência.

O princípio que trabalhou no subsolo nos séculos passados e que agora se tornou totalmente consciente é o princípio cristão-luterano, o da própria religião de Hegel. É o princípio da "santificação do mundo" que insiste na reconciliação do mundo e do divino, insiste no fato de que a justiça não será feita no fim dos tempos, ou no além, mas realizada neste mundo, aqui e agora. No texto de Weil, entretanto, há uma segunda formulação desse princípio. O princípio do progresso histórico é o princípio "rousseauista-kantiano". Esta segunda formulação especifica o que se entende por reino da razão ou por "realização da razão". Essa razão não é a razão calculista que está em ação na ciência e na tecnologia, não é a razão no sentido de Verstand (entendimento). É a razão no sentido de Vernunft. É a razão prática no sentido kantiano, a razão como vontade de universalidade. Mas a vontade de universalidade não caracteriza apenas a razão prática - o fato de agir segundo máximas admissíveis por todo ser humano - caracteriza a razão ela mesma, o pensamento. Porque pensar é produzir um discurso compreensível e válido para qualquer indivíduo que pensa. Do ponto de vista prático, entretanto, essa vontade de universalidade é uma vontade de liberdade. Éric Weil insiste nisso várias vezes: "A razão, com efeito, é liberdade, é a vontade que se compreendeu como vontade que quer a vontade livre" (Filosofia do direito, § 27; Enciclopédia, $3^{\text {a }}$ ed., § 481; HN, p. 134). Ele volta a isso no texto "A Filosofia do direito e a filosofia da história hegeliana". A razão é "a livre vontade de liberdade" (HN, p. 150). Todas essas fórmulas ecoam a tese apresentada por Hegel na Filosofia do direito (§ 27) e na Enciclopédia ( $3^{\mathrm{a}}$ ed., § 481) às quais Weil remete na nota de rodapé. A vontade livre é essencialmente vontade de liberdade. Essa tese fundamental é explicitada em Hegel e o Estado, obra magistral em que Weil analisa a Filosofia do direito de $\mathrm{Hegel}^{3}$.

A vontade livre é vontade universal de liberdade universal. Em termos concretos, isso significa que, em seu cerne, o objeto da vontade de universalidade é ver realizada a liberdade de cada ser humano na forma de direitos efetivos garantidos por instituições jurídicas, sociais e políticas. O que o ser razoável quer, mesmo que não tenha realmente consciência disso, o que ele não pode não querer, é o reconhecimento dos direitos fundamentais de todo membro do Estado como ser humano, nas instituições que regulam a vida da sociedade e do Estado. Em suma, ele quer a realização da liberdade na forma de um "Estado de direito", ou mais precisamente: um Estado do direito.

\section{Situação revolucionária e "enfermidade do Estado"}

Com base nisso, Éric Weil observa que Hegel não desenvolveu uma teoria explícita da revolução como um evento ou como um processo político. Ele explica isso pelo fato de que a

\footnotetext{
3 Cf. "o conteúdo de uma vontade livre e que não depende de um dado só pode ser a liberdade mesma. (...) a vontade livre só pode satisfazer-se compreendendo que ela busca e sempre buscou a liberdade numa organização racional, universal da liberdade". (WEIL, 2011, p. 41 s).
} 
Revolução Francesa, para Hegel, é de certa forma o "tipo-ideal" da Revolução como uma vontade de construir o mundo humano com base em princípios racionais, de refundar o Estado e a sociedade a partir do pensamento da liberdade. No entanto, a revolução como evento que irrompe na história é um sintoma de uma enfermidade de Estado. Em que consiste essa "enfermidade"? Ela pode afetar o Estado no sentido estrito do termo, ou seja, as instituições políticas e a administração: "Pode ser que o Estado, como tal, esteja enfermo, que suas leis, sua administração, seu poder central estejam, ou enfraquecidos a ponto de se tornarem ineficazes (caso do Santo-Império), ou em contradição com a sociedade em sua forma real (caso da França pré-revolucionária, caso, segundo toda probabilidade, da Grã-Bretanha de 1830)" (HN, p. 144). Vê-se que as enfermidades do Estado (no sentido estrito) são de dois tipos. No primeiro caso, o Estado deixa de funcionar: a) ou porque a sua administração é desorganizada, b) ou porque o poder central é enfraquecido em benefício de poderes locais ou de certos níveis intermédios da administração. No segundo caso, o Estado está enfermo porque não soube se adaptar às mudanças da sociedade. No caso da França do século XVIII, por exemplo, o Estado feudal está em contradição com uma sociedade que se tornou burguesa; os privilégios e dominação da aristocracia são agora insuportáveis em uma sociedade onde o poder econômico e social está nas mãos de uma burguesia de juristas, de comerciantes e de industriais (já na França, mas especialmente na Inglaterra), isto é, de pessoas para as quais o valor não está no nascimento, mas no exercício de "talentos".

Portanto, existe uma "enfermidade" das instituições estatais quando são ineficientes e desorganizadas, ou quando entram em conflito com uma sociedade cuja evolução torna obsoletas e insuportáveis as hierarquias tradicionais e o funcionamento atual do Estado. Existem, no entanto, outras enfermidades do Estado, que são as que afetam a sociedade civil ou a moral e a religião vivas, e que afetam em seguida todo o Estado. A enfermidade começa com uma crise social ou com uma crise da moral coletiva antes de se espalhar para todo o Estado. Aqui, não se trata mais de Estado no sentido estrito de instituições estatais: governo, administração, poder judiciário, parlamentos, etc. Trata-se do Estado no sentido da organização geral da qual a nação é dotada. Para entender isso corretamente, devemos ter em mente o plano da Filosofia do direito de Hegel. Uma primeira parte é dedicada ao direito abstrato (o direito da propriedade e dos contratos). Uma segunda parte é dedicada à moralidade subjetiva (individual). Uma terceira parte é dedicada à Sittlichkeit, ou seja, à "vida ética", que é a organização de conjunto de uma nação caracterizada por seus costumes, suas representações coletivas, seu sistema de valores. Tudo se apresenta na forma de esferas que se incluem umas nas outras. A Sittlichkeit compreende a família, a sociedade civil burguesa e o Estado. A família está incluída na esfera da sociedade civil, que é a esfera da produção e das trocas. E a sociedade civil está incluída na esfera do Estado, que é a organização consciente de uma comunidade histórica constituída por sua forma de vida e seu sistema de valores. Tudo o que diz respeito à propriedade e aos contratos, por um lado, e ao juízo moral dos indivíduos, por outro, encontra o seu lugar no contexto das relações familiares e nas relações sociais de trabalho e troca.

Por que as crises que afetam a sociedade civil causam enfermidades ao Estado? Porque a esfera da sociedade civil está incluída na esfera maior do Estado. Mais exatamente: a sociedade civil se interpõe entre a esfera familiar e a esfera propriamente política. Concretamente, isso significa que a participação na sociedade, o fato de nela exercer uma função, é um pré-requisito para ser membro do Estado. O pertencimento ao Estado é "mediatizado" pela participação na atividade socioeconômica. Para ser reconhecido como cidadão, o indivíduo deve primeiro ser reconhecido em seu justo lugar na sociedade. Se ele não é reconhecido no plano social, ele não é verdadeiramente reconhecido como cidadão. 
O que é, portanto, essa enfermidade da sociedade que se torna uma enfermidade do Estado? É o fenômeno da exclusão social, é o desenvolvimento de uma massa de indivíduos que são excluídos da sociedade porque não podem encontrar seu lugar nela:

É possível também que a sociedade esteja enferma: quando ela não oferece a todos e a cada um a possibilidade de nela se reconhecer, de aderir às suas leis, à sua moral viva, de nela se ver honrado em seu lugar, quando os homens, membros dessa sociedade, nela não podem ser satisfeitos material e moralmente (...) quando, em outros termos, existe uma classe determinada pela posição de seus membros no processo do trabalho social, onde se encontra uma injustiça infinita, um malfeito a homens membros da comunidade e, contudo, excluídos de uma comunidade que eles não podem viver (...). Com uma fórmula que não se encontra em Hegel neste contexto, essa sociedade peca contra os direitos do homem e do cidadão: incumbe ao governo corrigir esse erro fundamental (HN, p. 144 s.).

Aqui (HN, p. 145, n. 21), Weil se refere às páginas 110 e seguintes de seu livro Hegel e o Estado, onde desenvolve em particular o conteúdo dos §§ 241 a 245 da Filosofia do direito. Nestes parágrafos, Hegel mostra como a sociedade moderna - isto é, a sociedade nos inícios da industrialização, como era então exemplificada pela Inglaterra - engendra uma massa de indivíduos dessocializados, por um processo de crescente acumulação de riqueza, por um lado, e crescente pauperização, por outro. Essa massa de indivíduos dessocializados que Hegel ainda chama de "populacho" é o que Marx, um leitor atento da Filosofia do direito, chamará de "proletariado". O próprio Hegel fala disso como de uma "classe". No entanto, qualquer crise na sociedade que resulte na exclusão de uma massa de indivíduos dessocializados que não podem viver de seu trabalho - que não conseguem encontrar moradia, manter uma família ou viver de uma maneira que seja moralmente aceitável a seus olhos - põe em questão a realidade de seu pertencimento ao Estado.

O governo deve corrigir o mal imposto aos excluídos da sociedade, não apenas por razões morais, mas também por razões políticas. Porque a exclusão da sociedade também é exclusão do Estado. $O$ que significa ser cidadão quando não se tem atividade profissional, nem renda, nem moradia, nem família? A exclusão social torna a noção de cidadania vazia de sentido e faz dos indivíduos excluídos revoltados potenciais, não apenas contra a sociedade que os exclui, mas também contra o Estado que administra essa sociedade. O problema não é apenas moral, é também político, pois é aqui a unidade e a coesão do próprio Estado que estão ameaçadas.

Em poucas palavras, um dos problemas do Estado moderno, explica Weil em Hegel e o Estado, é o fracasso da mediação social pela qual passa o pertencimento do indivíduo ao Estado. Há outro problema, entretanto, que é o fato de que os Estados subsistem entre si em um "estado de natureza", que é um estado de violência. Mas a violência, em Hegel, indica falta de "mediação". Nesse caso, a guerra é uma possibilidade sempre presente, porque é a ultima ratio regum: é o que em última instância resolve as disputas. Segundo Weil, a Filosofia do direito indica aqui o lugar de uma mediação a ser encontrada, a de uma ordem internacional que ainda não existe.

E quanto às crises morais e religiosas? Por que elas também causam uma enfermidade do Estado? Desta vez, não se trata mais do fracasso da "mediação social" do pertencimento ao Estado. Trata-se da defasagem entre o Estado moderno e a "moral viva". De certa forma, esta é uma situação simétrica à da "fratura social". No caso de falha da "mediação social", o Estado deve se reformar e reformar a sociedade. Quando se trata das convicções morais e religiosas da nação, a reforma do Estado não terá sucesso se a reforma da moral viva não ocorrer. Eis como Weil coloca o problema: 
é possível também que os cidadãos de um Estado, sem nenhuma razão (social ou política), recusem-lhe sua adesão. O problema interessa a Hegel de modo particular, pois o considera o mais atual de seu tempo: por que, em determinado Estado, reina a confiança entre governo e administração, de um lado, e os cidadãos, de outro? Em última análise, porque nele a moral viva é a da reconciliação do universal com o particular, do espírito objetivo das instituições com a consciência moral dos indivíduos (...) porque, em uma palavra, a santificação do mundo aí não é considerada como uma impossibilidade, uma contradição (...) porque uma reforma fundamental, a Reforma, nele ocorreu e produziu seus efeitos sobre a atitude fundamental dos homens, sobre sua Gesinnung (...). Não há verdadeira revolução sem reforma da religião, isto é, desta moral viva da qual a religião é a consagração (HN, p. 145 s.).

A transformação da sociedade e do Estado é necessária. O objetivo é que todo indivíduo tenha seu justo lugar na sociedade para ter o seu lugar no Estado. Mas essa evolução da sociedade e do Estado só pode ocorrer se a moral viva da comunidade, seus hábitos, seus costumes, seu sistema de valores derem lugar à ideia de igualdade de todos os seres livres e razoáveis, bem como à convicção de que a justiça pode e deve ser realizada neste mundo. Para que o Estado faça jus à vocação de cada ser humano à autonomia moral, é preciso que a religião e a moral concreta da comunidade evoluam na mesma direção. Evidentemente, o problema é que a religião - mais precisamente, uma certa interpretação da religião - pode apoiar a antiga ordem. A crítica de Hegel tem como alvo as posições contrarrevolucionárias da Igreja Católica durante a Revolução Francesa e a Restauração que se seguiu à queda de Napoleão. Mas Weil tira disso uma consequência política que diz respeito à moral concreta em geral. Onde hábitos e convicções morais se opõem ao progresso social e político, a responsabilidade do homem de Estado será educar a nação, fazendo evoluir esses hábitos e representações coletivas.

\section{Revolta e revolução}

Então, essas são as grandes linhas da "situação revolucionária". Nesse contexto, o que dizer da própria revolução? Para compreendê-lo bem, deve-se notar que existe, em Éric Weil, um sentido negativo e um sentido positivo de revolução (CANIVEZ, 1989, p. 15-34). O sentido negativo é a destruição violenta das instituições existentes. O sentido positivo é a edificação de novas instituições. Os dois significados podem corresponder a dois momentos sucessivos do processo revolucionário: a destruição das antigas instituições, depois a construção das novas. Mas quando o momento negativo da destruição não é seguido pelo momento positivo da construção, a revolução no sentido negativo nem mesmo é uma revolução. É apenas uma revolta sem futuro. Em última análise, a atitude de revolta pode até se opor à vontade de revolução. Weil dirá isso em um texto intitulado "O Estado e a violência": o revoltado luta contra o poder, o revolucionário luta pelo poder (WEIL, 2000). A revolta contra qualquer ordem existente, contra qualquer tipo de poder, é um obstáculo à revolução que quer usar o poder para gerar uma ordem em princípio mais justa.

Em todos os casos, vê-se que a revolução não é mais que uma das consequências possíveis da situação revolucionária. Outras consequências da "enfermidade do Estado" são sua dissolução na anarquia ou a transição para o despotismo. Além disso, uma leva ao outro: a anarquia dos interesses egoístas leva ao despotismo que impõe a ordem em benefício de um indivíduo ou de uma classe dominante. Nessas condições, não há mais cidadãos, há apenas sujeitos no sentido político do termo, indivíduos que são sujeitados ao poder. Esses indivíduos não podem se reconhecer no Estado, eles não podem reconhecê-lo como seu Estado. É por isso que este Estado não pode contar com a sua lealdade, com a sua dedicação. O resultado dessa perda de coesão é que esse Estado pode ser destruído por uma potência estrangeira, como o 
Sacro Império Romano o foi por Napoleão, ou então conquistado como a Prússia em 1806. Em suma, a situação revolucionária pode levar à revolução como refundação do Estado. Mas a revolução não é senão uma das possíveis consequências da enfermidade do Estado. As outras possibilidades são o colapso do Estado em um ciclo de anarquia e despotismo, sua absorção por uma potência estrangeira ou sua redução à condição de Estado vassalo.

Quanto à revolução, ela pode ocorrer de duas maneiras. Por um lado, há uma revolução no sentido negativo - a destruição violenta das instituições - seguida por uma revolução no sentido positivo de edificação de novas instituições hipoteticamente mais justas. É o que o texto sobre o conceito de revolução em Hegel chama de "revolução popular" porque se baseia na mobilização das massas revoltadas. Por outro lado, a refundação do Estado se dá sem passar pela destruição violenta de antigas instituições. É o que acontece quando o Estado é dirigido por homens de Estado que compreendem a situação histórica e realizam as reformas necessárias. É o caso da Prússia após a invasão francesa. A refundação foi obra de ministros como Stein, Hardenberg, Gneisenau, que reergueram a Prússia após sua derrota militar. Deste ponto de vista, a Filosofia do direito de Hegel é um apelo à ação de tais ministros ou conselheiros, um apelo à ação reformadora de uma alta administração que compreenda a situação histórica, que saiba quais reformas é preciso empreender e que saiba como levá-las a termo. “O que Hegel pede para seu país natal é exatamente o que os reformadores prussianos, os Stein, Hardenberg, Gneisenau, etc., realizaram depois de lena. São estes homens que, fazendo a revolução do Estado, tornaram supérflua a revolução popular" (HN, p. 143).

Em suma, a transformação revolucionária do Estado pode ocorrer sem a passagem da revolta de massas. Mas, no texto intitulado "Hegel e o conceito de revolução", Éric Weil também especifica - ao atribuir esta tese a Hegel - que se a revolução "popular" ocorre, é porque o governo não soube empreender em tempo a necessária transformação da sociedade. Em qualquer caso, é sempre um governo que realiza a revolução, quer este governo tenha saído de uma revolução popular e levado ao poder por um movimento de massas, quer seja liderado pelo que Weil chama, em um texto intitulado "Massas e indivíduos históricos", um "líder conservador" que faz as reformas necessárias para preservar o Estado, sua unidade e coesão - e, por isso mesmo, a forma de vida da qual é a organização consciente ${ }^{4}$. "Não extrapolaríamos o pensamento de Hegel ao dizer que o povo pode se revoltar (...) mas que só o governo pode ser revolucionário (...). Para falar em paradoxos, a revolução se produz quando o governo não é revolucionário" (HN, p. 142).

\section{"A Filosofia do direito e a filosofia da história hegeliana". A concepção da história}

Em "Hegel e o conceito de revolução", a época em que Hegel vive, a época capturada por sua filosofia no pensamento, aparece como uma época de viragem. O princípio que foi a força motriz da história, o desejo que trabalhava inconscientemente a humanidade, chegou agora à consciência de si. Weil volta a isso no texto sobre "A Filosofia do direito e a filosofia da história hegeliana": "o motor do movimento é compreendido como a liberdade em si, agindo em vista

\footnotetext{
${ }^{4}$ Cf. "Masses et individus historiques", in Essais et conférences, T. II, Paris, Vrin, 2000. Este importante texto desenvolve a análise dos diferentes tipos de líderes revolucionários e de massa, como parte de uma análise da evolução das sociedades modernas desde os primórdios da industrialização. Permite-nos compreender como Éric Weil situa a sua própria reflexão política na "situação histórica" da segunda metade do século XX, tendo em conta a experiência dos 130 anos decorridos desde a publicação da Filosofia do Direito.
} 
de sua própria realização no mundo (...) e que, uma vez manifestada no mundo e sendo compreendida nele, não quer mais nada além de si mesma" (HN, p. 153). A história é, portanto, a passagem do em-si ao para-si, do em-si da vontade universal de liberdade universal ao para-si dessa vontade. Isso explica a possibilidade da Filosofia do direito. A Filosofia do direito é o desenvolvimento de todas as implicações concretas, em termos de instituições sociais e políticas, dessa vontade de ver a liberdade de todos institucionalizada na forma de direitos efetivamente garantidos pelo Estado. Essa apreensão conceitual é possível porque a vontade de liberdade não é mais uma vontade inconsciente de si mesma, mas uma vontade que se tornou uma vontade consciente de liberdade universal. A Filosofia do direito é o livro em que essa consciência é explicitada e desenvolvida na forma de um discurso coerente. Mas Éric Weil vai além. Por um lado, a Filosofia do direito não apenas dá conta de sua própria possibilidade como filosofia política. Ela responde pela possibilidade da própria filosofia. A história universal esboçada no final do livro mostra como o Espírito progrediu até o ponto em que chegou no presente, o ponto em que ele pode compreender a si mesmo na religião, arte, ciência e filosofia. "É a filosofia do direito que, delineando a Weltgeschichte, torna compreensível, não a filosofia no que ela ensina, mas a possibilidade e a realidade históricas de seu aparecimento" (HN, p. 158).

Nesse sentido, como disse na introdução, a filosofia da história hegeliana garante a transição, no sistema hegeliano, entre o Espírito objetivo e o Espírito absoluto. "Se a história tem um sentido e uma direção, é, então, em última instância, porque ela forma a base indispensável para a realização do Espírito absoluto" (HN, p. 157). Mas, por outro lado, Weil mostra como essa história é concebida de maneira retrospectiva, voltando do presente para o passado. É a partir do presente da época, dessa época marcada pela vontade revolucionária de liberdade universal, que Hegel concebe a história do gênero humano como a história dessa vontade, como a história da passagem dessa vontade do em-si ao para-si.

É assim que ele a concebe, mas não é assim que ele a narra. Ele a concebe indo do fim ao começo, mas narra progredindo do início ao fim, sendo o fim a época presente. Essa maneira de narrar dá conta tanto das bizarrias quanto da necessidade "metafísica" em ação nesta história. As bizarrias são o fato de que os heróis do Estado fundador aparecem exatamente na hora certa, como por milagre. Para sustentar tal cenário, é necessário pôr a ideia metafísica de uma necessidade imanente à história que explica sua progressão de época em época, desde o início até nós: uma necessidade que explica o surgimento, por exemplo, de um Napoleão. Isso é o que Hegel faz. Mas, para Weil, há uma contradição, em Hegel, entre a ordem da descoberta e a ordem da exposição, entre o fato de a história ser concebida de forma retrospectiva, indo do presente ao passado de onde provém, e o fato de que esta história é exposta no outro sentido, partindo do início para chegar ao nosso presente. Ao apontar essa discrepância, Weil abre o caminho para uma concepção não "metafísica" da necessidade histórica. Essa necessidade está ligada ao fato de que a narração é retrospectiva. Para chegar até nós, foi necessário passar por todas as etapas que levaram à nossa própria situação histórica, à forma de sociedade em que vivemos. Foi necessário passar por todas as épocas que conduzem ao nosso presente: se a história tivesse tomado outro curso, não é a nós que ela teria conduzido; ela não teria levado ao estado presente da humanidade. A tese é essencial, pois significa que o que aparece em Hegel como uma necessidade ontológica é, na verdade, uma necessidade inscrita na própria lógica da narrativa histórica. Além disso, vemos a consequência desta análise. Se a necessidade histórica é apenas retrospectiva, isso significa que o futuro não está escrito de antemão. Há espaço para ação. Muito mais, o futuro dependerá de nossa ação, das decisões que tomamos ou que não tomamos. A questão é se seremos capazes ou incapazes de resolver os problemas que se põem a nós, na situação que é a nossa no presente. $E$, para começar, o futuro dependerá de nossa 
aptidão a tomar coletivamente consciência da realidade desses problemas, a produzir a análise e a formulação corretas deles.

\section{A Filosofia política de Éric Weil e a Filosofia do direito de Hegel}

A partir dos dois textos que acabamos de examinar, podemos compreender como a Filosofia política de Éric Weil se situa em relação à Filosofia do direito de Hegel. Essencialmente, a diferença entre os dois autores reside na mudança de uma abordagem teórica (ou especulativa) da política para uma abordagem que enfatiza as modalidades e as problemáticas da ação ${ }^{5}$. Não é possível desenvolver totalmente aqui a comparação entre as duas obras. Vou, portanto, limitar-me a algumas observações, concentrando-me nos pontos que foram abordados acima, em particular na questão da revolução.

Como a Filosofia do direito de Hegel, a Filosofia política de Éric Weil é um livro que "apreende seu tempo no pensamento". É um livro que reflete sobre a situação histórica e, a partir dessa situação, desenvolve retrospectivamente uma compreensão da história ${ }^{6}$. A situação histórica é o rescaldo da Segunda Guerra Mundial, a luta contra o nazismo, o confronto entre os blocos soviético e ocidental, o início da descolonização, o processo de mundialização já claramente tematizado na Parte IV da Filosofia política. Nesse contexto, o problema central é o da violência, em um contexto histórico marcado pela experiência da violência do totalitarismo, da guerra e do extermínio em massa.

A questão essencial é saber como e em que condições a ação política pode progredir por meios não violentos, isto é, por meios democráticos, ou ainda: pela discussão conduzida no âmbito do que Weil chama de "Estado constitucional". Nessa perspectiva, o livro é suscetível de várias leituras. Como a República de Platão, este não é apenas um livro sobre instituições políticas, é também uma obra de educação. É um livro de educação política no sentido de que se esforça por conduzir o leitor à maneira propriamente política de pensar os problemas. É um livro que se esforça por educar o olhar do leitor sobre política. O livro parte da moral porque é a moral que, para o filósofo, dá sentido à ação política. Mas não basta a moral para pensar a política, ou seja, para pensar a própria ação. Em outras palavras, o livro tenta superar o conflito entre moral e política - entre Kant e Maquiavel, se preferir - ou ainda, o conflito entre a ética da convicção e a ética da responsabilidade tematizado por Max Weber. Mas, à luz das análises desenvolvidas nos textos sobre a Filosofia do direito de Hegel, também podemos dizer que a Filosofia política de Weil vai além da oposição entre o revoltado e o revolucionário. A educação política que o livro desenvolve dá lugar à revolta diante das injustiças e dos absurdos, mas como um "momento" dessa educação. A revolta é um momento pelo qual se passa, mas que deve ser superado para agir e pensar "politicamente".

O livro começa com a moral formal (Parte I), ou seja, com uma reformulação do formalismo kantiano. Continua com a análise da sociedade moderna (Parte II). Em seguida, passa ao

\footnotetext{
${ }^{5}$ Éric Weil apresenta sua Filosofia política como o desenvolvimento da categoria filosófica da Ação. A Ação é a última categoria "concreta" da Lógica da filosofia, aquela que faz pensar o modo de ser no mundo - atitude - que satisfaz inteiramente a exigência de universalidade que move a empresa. Encontramos aí a definição de revolução como ação segundo uma teoria: "O termo revolução não indica aqui a revolução 'popular' exclusivamente. Designa a dominação da 'teoria' sobre a 'realidade' e abarca tanto a 'revolução' platônica dos filósofos, que devem se tornar reis, quanto a dos funcionários públicos da filosofia do direito hegeliana, que devem organizar a sociedade no Estado para a satisfação razoável de todos os cidadãos, e, enfim, a revolução de Marx, na qual a parte mais 'alienada' da humanidade, ao tomar consciência de sua situação desumana, realiza a razão pela violência em vista de alcançar uma vida plenamente desenvolvida". (WEIL, 2012, p. 567, nota 2).

${ }^{6}$ Ver o estudo "Masses et individus historiques" citado acima.
} 
Estado (Parte III), terminando com a questão da organização política adequada a uma sociedade em processo de mundialização (Parte IV). A diferença com a Filosofia do direito de Hegel é imediatamente patente: o início da obra não é uma teoria do direito abstrato - não há teoria da propriedade na Filosofia política - e o final não é um esboço da história universal servindo de transição ao Espírito absoluto. Para não me estender muito, terminarei apenas com algumas observações, focalizando os temas abordados nas análises anteriores.

1 - A seção sobre a moral define os objetivos da ação política: garantir o reconhecimento universal dos direitos fundamentais, mas também garantir que a ação pode assumir o rumo da não-violência. Isso requer que indivíduos e grupos sejam capazes de fazer valer efetivamente seus direitos legítimos por meios moralmente aceitáveis, ou seja, por meio da discussão, e não da violência. Além disso, a moral fornece os critérios para uma análise crítica da sociedade, das desigualdades tradicionais, da discriminação, mas também das representações coletivas. Algumas revoltas são "progressistas", outras não: o sentimento de revolta não é em si uma justificação, porque a revolta pode ser a revolta de uma parte da sociedade contra a reafirmação, a seu ver injustificada, de certas vantagens tradicionais ou certas posições dominantes. Vimos acima a propósito dos obstáculos que a ação transformadora do Estado e da sociedade pode encontrar na moral concreta da comunidade: as convicções e as certezas morais de uma parte da sociedade - às vezes até a maior parte - podem opor-se a esta ação.

2 - A análise da sociedade moderna mostra como o surgimento de sentimento de revolta, de indignação, etc., é inelutável. Na verdade, ela mostra como a sociedade moderna funciona de tal forma que sentimento de injustiça e de não sentido surgem necessariamente. Os sentimentos de injustiça colocam os estratos superiores e inferiores da sociedade uns contra os outros. Eles dão origem a uma luta entre estratos sociais. O sentimento de insatisfação é um sentimento de não sentido. Ele opõe o indivíduo à sociedade, porque esta sociedade do cálculo, da competição, da técnica, não responde ao desejo de levar uma existência sensata. A revolta é, portanto, um momento inevitável e necessário na formação política do cidadão. Mas, por um lado, é preciso passar do sentimento de revolta ao discurso crítico argumentado. É preciso passar da violência do sentimento à capacidade de exercer juízo crítico na forma de discurso. Por outro lado, a passagem ao pensamento da ação e à ação pelo pensamento supõe não se deter no ponto de vista da revolta. É preciso que a crítica do poder leve a uma reflexão sobre os problemas que um exercício sensato de poder tem por tarefa enfrentar. A educação política, ou seja, a educação ao modo político de pensar, pressupõe passar da atitude de revolta a uma análise dos problemas que se põem à sociedade e aos Estados modernos, análise que abre caminho para uma verdadeira teoria da ação coletiva.

3 - Esses problemas são desenvolvidos na terceira e quarta partes do livro, que são respectivamente dedicadas às relações internas e externas do Estado. Em linhas gerais, trata-se das duas mediações inacabadas apontadas em Hegel e o Estado. Trata-se de remediar o fracasso da mediação social da relação do indivíduo com o Estado assim como a falta de mediação nas relações interestatais. Weil reelabora essas questões de acordo com a situação histórica que é a da segunda metade do século XX (e que ainda é a nossa, no início do século XXI). Por um lado, o problema fundamental do Estado moderno será conciliar a justiça e a eficácia, particularmente a justiça social e a eficácia econômica. Por outro lado, Weil mostra que o interesse dos Estados modernos é implementar uma administração global da sociedade no processo de mundialização ${ }^{7}$ - um problema particularmente atual, dado que enfrentamos problemas de

\footnotetext{
7 Para um desenvolvimento detalhado, cf. (CANIVEZ in PERINE; COSTESKI, 2016, p. 13-31).
} 
dimensão mundial que requerem uma ação em escala "global": problemas de desenvolvimento econômico, segurança coletiva, pandemias, degradação ambiental, etc.

A Filosofia política teoriza a ação coletiva por meios democráticos, ou seja, no quadro da legalidade constitucional. Pode-se dizer que, para Weil, a ação é por definição "revolucionária" porque ela visa o exercício do poder para transformar a sociedade e o Estado. Mas esta transformação "revolucionária" da sociedade pode assumir a forma de legalidade democrática ou ser alcançada através da violência, sob o risco de destruir as instituições democráticas. Éric Weil evoca com insistência, em sua Filosofia política, que o surgimento de um fundador-revolucionário é sempre possível. Isso significa que a revolução pela violência sempre pode explodir, onde a revolução por meios democráticos ou constitucionais não tiver ocorrido - assim como no texto sobre "Hegel e o conceito de revolução", se via que a revolução "popular"ocorre quando o governo não é revolucionário. $O$ "motor da história" em Weil não é a guerra como em Hegel, ou a revolução "popular" como em Marx. São os dois ao mesmo tempo. Mas não é a violência da guerra ou da revolução (em sua fase negadora) que por si só traz o progresso. O que é fonte de progresso é o que precisa ser feito para evitar tanto uma quanto a outra. Nas democracias constitucionais ${ }^{8}$, é a possibilidade sempre presente da guerra e da revolução violenta que deve levar os governantes a agir, fazendo as reformas necessárias, inclusive as mais radicais, tanto no interior do Estado e da sociedade quanto no plano das relações internacionais.

Éric Weil, portanto, permanece fiel à ideia de que a ação autêntica é em essência revolucionária. Paradoxalmente, essa fidelidade o leva a rejeitar, como Hegel, o culto da revolução pela revolução (da revolução entendida como a destruição das instituições existentes). Esta é a conclusão do texto sobre "Hegel e o conceito de revolução": "o culto da revolução pelo amor da revolução é insensato" (HN, p.147). Por trás dessa posição, não há apenas um fundamento moral e legalista, ou seja, uma preferência filosófica pela ação por meio da discussão. Existe também uma experiência histórica. Se Weil está longe de condenar o princípio da revolução soviética, ele conheceu a revolução nacional-socialista. Ele sabe que nem todas as revoluções são progressistas. Existem revoluções que, se bem-sucedidas, conduzem a uma regressão do direito e da justiça. A revolução que passa pela destruição das instituições existentes pode levar a um regime mais justo - é o caso da Revolução Francesa, embora esse resultado só tenha sido alcançado cem anos depois, após a queda do Segundo Império e a criação do Terceira República. Mas também pode desembocar no ciclo anarquia-tirania que permanece em toda parte, diz Weil, "um perigo não imaginário" (HN, 147). A revolta de massa pode engendrar um regime de violência e arbitrariedade. A ditadura do partido revolucionário em princípio provisório pode converter-se em uma oligarquia de "nomenklaturistas". As paixões nacional-populistas podem causar um retrocesso da "moral concreta" da nação, um renascimento dos preconceitos étnicos, ideológicos, religiosos, culturais, etc. que se acreditava superados É também um lembrete de que não há necessidade histórica senão de um ponto de vista retrospectivo, como diz o texto sobre "A Filosofia do direito e a filosofia da história hegeliana". A história do futuro não é necessariamente a de um progresso contínuo. Também não é necessariamente de um inelutável declínio. O futuro depende inteiramente de nossa capacidade de apreender e lidar com os problemas do presente.

\footnotetext{
${ }^{8}$ A expressão agora é comum no vocabulário da teoria política. Tem a vantagem de fundir o conceito de Estado constitucional e a ideia weiliana de democracia como método de governo baseado na "discussão universal", ou seja, na participação de todos os cidadãos no processo de decisão coletiva.
} 


\section{Referências}

CANIVEZ, Patrice. A revolução, o Estado, a discussão. Síntese. Belo Horizonte, maio/agosto, 1989.

CANIVEZ, Patrice. A teoria weiliana da mundialização. In: PERINE, Marcelo; COSTESKI, Evanildo. Violência, educação e globalização. Compreender o nosso tempo com Éric Weil. São Paulo: Edições Loyola, 2016.

HEGEL. F. Philosophie der Weltgeschichte. Paris: Ed. Lasson, 1923.

WEIL, Eric. Hegel e Nós. Org Valdério, Francisco et. al. Caxias do Sul: Educs, 2019.

WEIL, Eric. Hegel e o Estado. Trad. C. Nougué. São Paulo: É Realizações, 2011.

WEIL, Eric. Lógica da Filosofia. Trad. Lara C. de Malimpensa. São Paulo: É Realizações, 2012.

WEIL, Eric. L'État et la violence. In: Essais et conférences, T. II. Paris: Vrin, 2000.

WEIL, Eric. Philosophie et réalité. Vol. I. Paris: Beauchesne, 2003.

\section{Sobre o autor}

\section{Patrice Canivez}

Doutor em Filosofia. Professor da Université Lille 3 e Diretor do Instituto Eric Weil em Lille, França.

Recebido em: 10.07.2021.

Aprovado em: 16.07.2021.
Received: 10.07.2021.

Approved: 16.07.2021. 